\title{
Silviano Santiago e a desconstrução: ENTREVISTA COM SiLViano SANTiago
}

\author{
Raphael Meciano
}

\begin{abstract}
Resumo: Trata-se de entrevista concedida em 14 de agosto de 2016 por Silviano Santiago, ensaísta, poeta e romancista. Nascido em Formiga, Minas Gerais, em 1936, é autor de um vasto trabalho intelectual e artístico, tendo iniciado sua formação em Letras no Brasil e a completado na França, concluindo seu doutorado na Sorbonne em 1968. Foi professor no Brasil (PUC-Rio) e no exterior, passando pelas universidades de Rutgers, Toronto, Nova York, Buffalo, Indiana e Novo México. A entrevista aborda o papel de Silviano Santiago no debate intelectual brasileiro, sua leitura da obra de Jacques Derrida e seu papel na disseminação do pensamento deste autor no Brasil.

Palavras-chave: Silviano Santiago; desconstrução; pós-colonialismo.
\end{abstract}

1. Em primeiro lugar eu gostaria de lhe perguntar em que contexto e de que maneira começaram suas leituras de Derrida. Quer dizer, quais eram os problemas intelectuais que lhes eram caros quando do encontro com os textos de Jacques Derrida?

Ocupo-me, primeiro, do contexto. Defendi tese de doutorado na Sorbonne às vésperas dos acontecimentos de maio de 1968. Entreguei a tese em janeiro daquele ano e, à espera da data prevista para a defesa (fins de abril), fiquei gratuitamente assuntando o que se passava na cena parisiense dentro do meu quartinho de hotel na Rue Cujas. Respondoà sua pergunta menos pelo desenvolvimento das ideias e mais pela bibliografia assumida até então, ou seja, pelos autores e pelos livros preferidos em crítica e história literária. Ainda na graduação em Minas Gerais e no

1 Mestrando em História Social pela Faculdade de Filosofia, Letras e Ciências Humanas da Universidade de São Paulo - FFLCH/USP: meciano.raphael@hotmail.com. 
ano e meio de estudos especializados no Rio de Janeiro, minhas leituras de crítica contemporânea iam de Claude-Edmonde Magny (destaque: o notável e esquecido L'âge du roman américain) a Jean-Pierre Richard (destaque: Poésie et profondeur), Jean-Paul Sartre (destaque: o Baudelaire) e ao primeiro Roland Barthes (Le dégré zero de l'écriture, curiosamente citado por Antonio Candido em 1959 na Formação). Em virtude das aulas ministradas na UFMG (Universidade Federal de Minas Gerais) por um grande professor de literatura espanhola, José Carlos Lisboa, também lia a crítica estilística espanhola, Dámaso Alonso (destaque: Poesía española) e Carlos Bousoño (destaque: Teoría de la expresión poética). Aqui e ali, muita leitura em História, Sociologia e estética cinematográfica, alguma em Filosofia.

Em virtude da pesquisa e redação da tese, meu forte, naqueles anos, eram os críticos que trabalharam a crítica genética ou a vida e a obra de André Gide. Poucos deles causaram-me verdadeiro impacto, a não ser Jean Prévost, La création chez Stendhal, Jacques Hadamard, Essai sur la théorie de l'invention dans le domaine de la mathémathique, e a biografia de Gide por Jean Delay. Entre os bons antigos, li bastante Charles du Bos e Ramón Fernandez.

À espera da data prevista, aproveitei para me aproximar de modo um tanto definitivo do que seria chamado de teoria pós-estruturalista ou pós-moderna (já estava a par do momento anterior, chamado estruturalismo formal, de que é exemplo A. J. Greimas e o segundo Barthes). O resumo das minhas leituras desse período está na eleição contrastiva - em diferença, explicito desde já o peso derridiano nas minhas preocupações - das categorias de análise e interpretação, desenvolvidas em ensaio que encontrará abrigo ao final de Uma literatura nos trópicos. Acrescento que às minhas preocupações propriamente europeias, tenho de acrescentar o interesse crescente pelas pesquisas críticas norte-americanas (por razões financeiras, passei a ensinar na universidade norte-americana em setembro de 1962, antes de terminar a tese, ou seja, logo depois de ter-me inscrito na Sorbonne e trabalhar por um ano em Paris sob a orientação do professor Pierre Moreau, a quem serei eternamente grato).

Minhas novas leituras em inglês se acoplavam a livros lidos nos anos 1950, de autoria de Ezra Pound e de T. S. Eliot, e enriqueciam certas preocupações minhas, bem pessoais, no tocante à compreensão ampla da literatura brasileira. Como tinha de dar os famosos survey courses na universidade norte-americana, apelei para a explication de texte, 
então minha especialidade em didática, oriunda dos bons professores franceses. Escolhi textos que iam de 1500 ao presente, ${ }^{2}$ tendo adotado, na leitura em sala de aula, o ponto de vista pós-colonial (em detrimento da preocupação dos mestres brasileiros que estudavam a contribuição artística propriamente nacional da perspectiva da sua formação, ou seja, a partir dos momentos decisivos - aprecio o adjetivo - em que a literatura escrita no Brasil se torna digna do adjetivo brasileira).

Entre o estudado, o assimilado e o intuitivo, no campo estreito da expressão artística na América Latina (a eleição do campo não foi desejo meu, foi outro recurso didático, já que o bom aluno norte-americano chegava ao estudo do português bem empacotado em sólido conhecimento dos autores e críticos hispano-americanos), eu procurei trabalhar o que fui redescobrindo da literatura brasileira a partir de uma rede de conceitos que seria liberada - a partir dos anos 1960 - não só pelos escritos de Roland Barthes e de Michel Foucault, como pelos de Gilles Deleuze e do caçula de todos, Jacques Derrida.

No caso deste, esclareço, não me senti então (refiro-me aos anos 1962 e 1964, passados na Universidade do Novo México) em terreno totalmente estranho quando me adentrava em 1970 pelas noções básicas de descentramento e de desconstrução, por exemplo. Já as trabalhava intuitivamente. Refiro-me, por exemplo, ao descentramento que eu operava na noção exclusiva de formação. Refiro-me à desconstrução do etnocentrismo (a carta de Vaz Caminha era o melhor exemplo) e até mesmo do falocentrismo (vide ensaio sobre Iracema). Por isso, atrevo-me a dizer-lhe que, em fins dos anos 1960, atingi - por razões que não chego a explicar racionalmente - um patamar acima na escada constituída por degraus cimentados pela nossa literatura e pela literatura europeia, pelo pensamento crítico brasileiro e pelo pensamento crítico europeu, degraus que iam sendo ajustados pelos primórdios da contribuição anglo-saxônica em Cultural studies.

Desse período há algo de escrito. Está no ensaio "A palavra de Deus", que se encontra na revista Barroco (n. 3, 1970), dirigida por Affonso Ávila, e também em anterior, "Iracema: alegoria e palavra" (Luso-Brazilian

2 Na releitura da entrevista, lembro que adotei como manual na Universidade do Novo México os três volumes da antologia organizada por Castello e Candido. Sabemos, hoje, que a produção dos dois uspianos se complementa. A livraria da universidade encomendava os livros adotados a Susan Bach, notável e honestíssima, embora careira, comerciante carioca, de que os especialistas em ensino no estrangeiro nunca falam. 
Review, winter 1965). Com a ajuda de Haroldo de Campos, que admirava o ensaio sobre Alencar, ele foi logo depois publicado, integralmente, no suplemento literário de $O$ Estado de São Paulo (Nilo Scalzo era então o diretor do suplemento). Muito do período está também na leitura que fiz e publiquei da melhor coleção de poemas do período, Código de Minas (1969), de Affonso Ávila. Com a ajuda dos conceitos de apropriação e de transgressão, comentava todo o trabalho de desconstrução dos lugares-comuns da mineiridade efetuado pelos poemas do Código de Minas. E está finalmente na interpretação do poema "Infância", de Carlos Drummond, posteriormente alicerce do meu livrinho sobre o grande poeta, publicado pela Editora Vozes, em 1975. Ali, esboço a criaçãopoética-como-leitura, no caso, leitura pelo menino itabirano da história de Robinson Crusoé ("comprida história que não acaba mais") constitutiva mais tarde do que chamarei de mito do começo, ${ }^{3}$ em oposição ao mito de origem, desenvolvido a partir dos valores transmitidos pelo clã familiar à criança. Na constituição do indivíduo no mundo infantil do Drummond modernista importa mais a experiência da leitura do que a experiência da vida vivida em família ou na comunidade (ao contrário do que acontecerá no romance nordestino da mesma década). Daí a famosa constatação em Confissões de Minas: "Como foi que a infância passou e nós não vimos?".

Não menciono, porque não é do interesse desta entrevista, meu romance $O$ olhar, terminado em 1960, recusado pela Civilização Brasileira e finalmente editado graças ao amigo Rui Mourão pela Imprensa Oficial de MG, em 1974. Por ser também ridículo não o mencionar, lembro que o romance foi escrito - e esta informação está no prefácio da segunda edição em 1983 pela Global - seguindo um fio condutor, um modelo bem pessoal estruturante da ficção: a infância de Charles Baudelaire, tal como foi sugerida a mim por Jean-Paul Sartre, e que escrevi com o estilo de Clarice Lispector, para dar de presente a Lúcio Cardoso. Evidentemente, o romance não teve repercussão. Perdoe se transgrido os limites estabelecidos pelas perguntas, mas essas coisas todas se misturam se me pede(m) para falar do contexto das (minhas) primeiras leituras de Jacques Derrida. Há o contexto anterior e há o posterior. Afinal, só tolos ou ressentidos (e como os havia! bem antes das redes sociais) acreditam que as ideias estrangeiras são adquiridas no píer da Praça Mauá, em caixões que chegam por navio da Europa.

${ }_{3}$ Cf. Ian Watt, The Rise of the Novel, e C. B. Macpherson, A teoria política do individualismo possessivo. 
Em fins de 1968, depois da leitura dos primeiros livros de Derrida, publicados em 1967, regresso doutor de Paris e viajo a Toronto, onde ensino por um ano na Toronto University, e em seguida, em setembro de 1969, passo à State University of New York at Buffalo, onde sou contratado pelo chairman, John Simon, de um French Department que se diferencia e se atualiza por apresentar como linha de pesquisa dominante o pós-estruturalismo. Minha tese, onde metodologicamente se detecta o T. S. Eliot dos estudos sobre Shakespeare disseminado pelo que será o pós-estruturalismo, contou muito na hora da contratação, mas contaram também minhas leituras paralelas feitas em Paris em 1968 e principalmente o nome que já tinha adquirido como professor de literatura em outras universidades norte-americanas. O novo posto foi a ocasião suficiente para assentar melhor o conhecimento gratuito propiciado pela espera do dia da defesa de tese. Em 1969, tornei-me Associate Professor em francês, colega de René Girard, Olga Bernal, Eugenio Donato, Raymond Federman etc., num departamento que tinha como convidados muitas das grandes figuras de Paris, já mencionadas.

Nessa época ponho no papel o ensaio "L'entre-lieu du discours latino-américain" (1971). Não foi por cabotinismo que o escrevi originariamente em francês. A convite de Eugenio Donato (cf. The Structuralist Controversy, antologia pioneira organizada por ele e Richard Macksey), apresentei-o num simpósio na Universidade de Montreal, de que participaram René Girard e Michel Foucault. A questão do bilinguismo canadense, levantada por De Gaulle, era candente naquele momento e foi substantiva no momento em que pensei a ideia de entre-lugar. A palestra causou alguma repercussão e foi logo traduzida ao inglês por Judith Mayne, aluna minha, e publicada em plaquete por Buffalo com o título de Latin-American Literature: The Space In-Between (1973). ${ }^{4}$ Antes, em 1972, tinha editado um número especial da revista Modern Languages Notes dedicado a narrative analysis e Greimas, a pedido dos colegas da Universidade de Johns Hopkins. Pedi licença sem vencimentos em Buffalo e passei grande parte do ano de 1972 a ensinar pela primeira vez na universidade brasileira. Regresso logo a Buffalo porque sou eleito Acting Chairman do Departamento de Francês. Em 1974, volto definitivamente ao Rio de Janeiro e passo a ensinar no Departamento de Letras da PUC-RJ.

4 Thomas (Tom) Kavanagh escreveu gentilmente a nota introdutória. Era então um jovem doutor. Hoje é titular em Literatura francesa na Yale University. 
Em 1976, pedi demissão ao Departamento de Francês da State University of New York at Buffalo. Tinha recebido tenure em 1970.

\section{Gostaria de lhe perguntar também a respeito do contexto do curso da pós-graduação em Letras, na PUC-Rio, em 1976 (imagino que seja esta a data correta), em que o senhor realizou a organização do Glossário de Derrida. Pelas informações que tenho, Derrida não era o único autor lido naquele curso; nesse sentido, por que a inciativa do Glossário? (Quer dizer, por que não um Glossário de Foucault ou Barthes)}

Já em 1972, durante um curto período em que fui convidado pela diretora Amélia Lacombe e pelo poeta Affonso Romano como visitante na PUC-RJ, ofereci um seminário de pós-graduação sobre Jacques Derrida e outro, paralelo, onde apresentei - sem a aparência do picadinho que lhe foi oferecido até agora - minha primeira leitura pós-colonial da literatura brasileira. O segundo seminário se intitulava "A semente, ou da impossibilidade de se escrever a origem" ${ }^{5}$ e era visivelmente inspirado pelas minhas aulas nos Estados Unidos e pelo que aprendera com Jacques Derrida, Louis Althusser (Lire le Capital) e muitos críticos e historiadores. O seminário retraçava o percurso colonial e pós-colonial da metáfora da semente (semen est verbum Dei - a principal semente a ser plantada na terra descoberta), textual na Carta de Vaz Caminha, passando pelo pessimismo do Sermão da sexagésima (calcado na parábola do semeador) de Vieira e pela sexualização (sêmen) em Iracema, de Alencar, chegando até o derrotista Policarpo Quaresma, de Lima Barreto. ${ }^{6}$ A metáfora tomada originalmente de empréstimo à Bíblia sagrada - alicerçava e se

\footnotetext{
$5 \mathrm{O}$ resumo da proposta do seminário está em cinco folhas mimeografadas, que distribui aos mestrandos. Infelizmente, não tenho mais cópia delas. Concorri com o projeto a uma bolsa Guggenheim; evidentemente, não fui contemplado e fiquei sem escrever o livro. Espero ter ficado evidente que origem (impossível de ser detectada sob a forma de escrita) se opõe a começo, caro aos historiadores oitocentistas da formação e ao Drummond do poema "Infância". O desenvolvimento do contraste poderá ser encontrado no ensaio "A atração do mundo" (O cosmopolitismo do pobre).

6 Se o curso não tinha o caráter de "picadinho", a redação dos trabalhos escritos teve. Tudo meio solto. Para os dois primeiros casos, o já citado "A palavra de Deus" e, para Alencar, "Alegoria e palavra em Iracema", também já citado, e "Liderança e hierarquia em Alencar" (Vale quanto pesa). A leitura de Lima Barreto está no ensaio "Uma ferroada na ponta do pé" (Vale quanto pesa).
} 
disseminava pelos sucessivos textos da literatura brasileira, semântica e ideologicamente. Já tinha lido, obviamente, o premonitório Colonialismo e Evangelho, de Joseph Höffner, publicado em espanhol desde 1957 (se não me engano, traduzido e publicado pela Editora da USP/Presença em 1973).

O seminário sobre Derrida fazia pendant ao seminário sobre a semente, ou vice-versa - talvez seja esta a melhor resposta que possa dar à sua pergunta "por que o interesse por Derrida na hora do glossário, e não por Barthes ou por Foucault".7 Como a questão Jacques Derrida era também desnorteante em termos do ensino da literatura no Brasil, escrevi uma apostila para os mestrandos (a PUC ainda não estava credenciada pela Capes a oferecer os cursos de doutoramento). A apostila, "Desconstrução e descentramento", é recebida pela comunidade restrita como introdução ao estudo de Jacques Derrida, mas é aceita como ensaio e publicada no ano seguinte na revista Tempo Brasileiro, de Eduardo Portella (n. 32, 1973, pp. 76-97).

Devido à boa recepção obtida pelos dois seminários, a que devo associar um terceiro sobre manifestos literários, do Futurismo italiano em 1909 à Poesia Concreta em 1958 (onde desenvolvo a distinção entre paródia, pastiche e apropriação, já trabalhada no romance $O$ olhar e posteriormente trabalhada no livro de poemas Crescendo durante a guerra numa província ultramarina e no romance Em Liberdade), eu sou convidado como professor na PUC a partir de março de 1974. Retomo o seminário sobre Jacques Derrida, mas com uma preocupação didática que julguei importante. A maioria dos mestrandos não tinha um conhecimento do francês compatível com o estilo raciniano de Derrida (como bom estrangeiro, ele escreve francês mais elegantemente do que os colegas educados na margem norte do Mediterrâneo - compare-se um texto dele ao de contemporâneo - de Sartre, por exemplo, - e entenderão o que digo do ponto de vista estilístico).

7 É pelo menos divertido constatar que nunca se pergunta a Schwarz "por que escreve o texto ‘Um seminário de Marx' (Sequências brasileiras)?”. Seria porque os leitores somos medrosos ou enrustidos diante das manifestações do imperialismo acadêmico no Brasil, embora sejamos valentões ou machos em relação às minorias propriamente artísticas? Lembre-se que, naquele ensaio, Schwarz se refere a "certa indiferença [dos estudiosos de Marx] em relação ao valor de conhecimento da arte moderna, incluída a brasileira”, para concluir que "isso fez que os achados fortes do seminário não se aliassem produtivamente ao potencial crítico espalhado nas letras e na cultura ambiente, ficando confinados ao código e ao território acadêmico, dizendo e rendendo menos do que poderiam”. 
Decidi enfrentar, com a ajuda dos mestrandos, razão para o seminário, várias dificuldades. Eleger os por assim dizer "conceitos" (na linguagem derridiana, trata-se na verdade de indécidables) mais salientes da escrita derridiana. Assimilá-los bem no original. Tentar transportá-los para a língua portuguesa com conhecimento de causa e rigor. Etc. A turma foi dividida em quatro grupos, por sorteio. Cada grupo trabalharia com bastante independência a experiência de leitura em seminário e a individual, e redigiria os verbetes. Ao final, o professor, com a ajuda da mestranda Ana Maria Skinner, que tinha excelente conhecimento de francês e já era tradutora, cotejaríamos as quatro versões (todas anônimas) e iríamos selecionando os "verbetes" que nos pareciam mais próximos da proposta geral do seminário. O Glossário de Derrida, tal como foi primeiro mimeografado e entregue à comunidade da PUC (1974), e, posteriormente, tal como foi publicado pela Francisco Alves (1976), é o resultado coletivo de dois seminários sucessivos. Evidentemente, nunca agradecerei suficientemente a generosa acolhida que tive por parte dos mestrandos.

3. Quero adentrar, agora, ao assunto do debate intelectual que envolve as leituras de Derrida no Brasil e da prática da “desconstrução". Mormente, uma das características marcantes, e talvez centrais, em seu trabalho é a leitura desconstrutiva da Formação da literatura brasileira, de Antonio Candido. Leitura esta que lhe permite reavaliar a história da literatura brasileira pela perspectiva chamada de pós-colonial. Em conferência dada pelo senhor na Universidad Nacional de Tres de Febrero, em Buenos Aires (2014), fica bem delineada a necessidade de uma reavaliação dos discursos de formação nacional em benefício de outra perspectiva a respeito da literatura brasileira. Gostaria, então, que o senhor comentasse essa distinção.

Sou obrigado a lhe responder, dizendo que já respondi por escrito à pergunta que formula. Vou-me repetir, e mal. Lamento.

Quando a Universidad Tres de Febrero (Buenos Aires) concedeu-me o título de Doutor Honoris Causa, julguei oportuno fazer um "depoimento" sobre o caminho que segui para adotar, que segui até chegar a adotar uma 
metodologia pós-colonial na leitura do corpus da Literatura brasileira. ${ }^{8}$ Evidentemente, a palestra começa pela desconstrução do conceito de formação (Bildung, em alemão; às vezes pode significar em inglês, self-fashioning), tal como expresso na história da literatura pelo mestre dos mestres da minha geração, que é Antonio Candido, e, mais evidentemente, pela importância do conceito na minha própria formação de estudioso das Letras. Observo inicialmente a estranha polissemia de formação: tanto se refere à "formação" do Brasil contemporâneo (expressão, aliás, de Caio Prado Jr.) a partir dos ideais do século 18 iluminista, quanto à "formação" doutoral do crítico na Universidade de São Paulo e, ainda, à "formação", a partir de 1959, de todo e qualquer jovem logo após o vestibular em Letras. Há um valor e uma beleza juvenil e mágica no conceito que me encantam, pois tanto o Brasil nação quanto o jovem professor e, ainda, o jovem estudante estão em vias de chegar à plenitude de suas respectivas e variadas vidas. Todos - literatura brasileira, aspirante a doutor e eterno calouro - passam pelo começo da maturidade, pela independência na constituição das próprias e respectivas identidades. As metáforas de caráter orgânico são sempre mais simpáticas que as de caráter mecânico, isso desde que René Wellek levantou a lebre na sua histórica da crítica. A cara juvenil da literatura nacional, soberana em Ouro Preto no século 18 , se confunde com a mente doutora do mestre que se confunde com o aprendizado estudantil do aluno. Pela magia da ordem cronológica, os três, unidos, vivem o lento, sofrido e gradativo processo de interiorização ${ }^{9}$ de um saber que lhes é exterior, embora cada um e os três saibam que, sem a apreensão histórica e crítica daquele saber estranho, daquele saber estrangeiro, intruso, não conseguiriam elaborar o alicerce indispensável para a grandeza plena das respectivas personalidades maduras.

Graças aos sucessivos anos de estudo e às lições explicadas pelo professor em aula, o aluno pode adquirir o saber e dele ser mestre

8 Cf. "A literatura brasileira da perspectiva pós-colonial - um depoimento". A palestra foi publicada em espanhol pela Universidad Tres de Febrero (Buenos Aires). Na nossa língua, saiu um resumo na "Ilustríssima" da Folha de S. Paulo. Consultar também a coluna que escrevi para o suplemento Sabático, "Formação e inserção", hoje no livro Aos sábados pela manhã (Rocco).

9 Paulo Eduardo Arantes, da atual geração de titulares da USP, informa os estudiosos sobre - e o cito - "a formação [sic] da filosofia uspiana (uma experiência dos anos 1960)". Arantes aproveitou a oportunidade do adjetivo uspiano [?] a qualificar o substantivo filosofia, para lançar sua irônica defesa da boa formação segundo os critérios iluministas: "[...] afinal um pastiche programado em início de carreira é bem melhor do que uma vida inteira de pastiches inconscientes". 
pela sua interiorização gradativa e espinhosa. Ou pode adquirir - em tempos pós-modernos - o saber pela forma de sua exteriorização, que é proporcionada como reserva, como estoque, a todo e qualquer consulente, sob as bandeiras institucionais mais variadas, como bibliotecas, museus, acervos, laboratórios de pesquisa, programas na Internet, atualizados quase que diariamente etc. etc.

No antigo processo de interiorização do saber, o cidadão ganhava direito à palavra subjetiva depois de se entregar, desde a mais tenra idade, a um lento e progressivo processo de assimilação do saber, tanto de um saber universal e multidisciplinar básico, quanto de um saber disciplinar e superior, que lhe fornecia o passaporte seguro para sua profissionalização na sociedade liberal ou neoliberal. No antigo processo de aquisição, a escola e os professores eram donos de uma informação completa do saber e, por isso, eram os principais responsáveis pela educação junto às novas gerações que, por definição, teriam sempre informações insuficientes. O desnível justificava a autoridade dos professores e a obediência (ou o "pastiche consciente", apud Paulo Eduardo Arantes) dos alunos.

Em época que me tocou viver com intensidade no estrangeiro, o processo de aquisição do saber começava a se dar através de experiência bem diferente da oferecida a mim na UFMG e até mesmo na Sorbonne. ${ }^{10}$ Com a proliferação de magníficas bibliotecas públicas e universitárias (por sorte minha, as conheci no início dos anos 1960 tanto na França quanto nos Estados Unidos), com a multiplicação de museus (idem) cada vez mais diversificados e especializados, com o surgimento dos mais variados tipos de arquivos públicos, com a proliferação infinita de laboratórios e de grupos de pesquisa (o glossário, sempre referido, foi minha primeira experiência), com o trabalho coletivo em torno de memória científica específica, e com a consequente informatização de todas essas instituições e também do conhecimento universal, o saber passa mais e mais a viver a condição de uma "explosiva exteriorização"

10 Tive a oportunidade de conhecer pessoalmente Ivan Illitch, futuro autor de Deschooling Society (1971), quando eu ainda ensinava na Universidade do Novo México e ele se sustentava com um centro de ensino de línguas estrangeiras em Cuernavaca. Ivan começava a expor suas ideias sobre educação em palestras que se tornariam populares no ambiente estudantil da Universidade de Berkeley. Daquele livro, retiro um dos motores do seu pensamento: "Acredito no movimento. Não acredito que ninguém possa aprender nada sentado, calado, imóvel e passivo, ao lado de outros moscas-mortas, absorvendo como uma esponja a pseudosabedoria que um professor despeja”. Ele é ainda o criador da expressão "baby-sitting system" para qualificar o ensino pequeno-burguês institucionalizado. 
(cf. Jean-François Lyotard, A condição pós-moderna, 1979)." Ele é oferecido a todos e a qualquer - independentemente do processo de sua interiorização no aluno pelo professor e pela escola - e se torna tanto mais accessível e público quanto for mais abundante. O professor e a escola já não podem mais exigir uma absurda interiorização do saber por parte do aluno, mesmo porque, professor e aluno, em condições de Primeiro Mundo e de Brasil futuro, trabalham ambos com informação completa. Em quantidade de informação, não há mais desnível entre professor e aluno. Há complementaridade na pesquisa coletiva, independentemente de faixa etária. Ensinam-se não só os conteúdos, como nos velhos tempos da interiorização do saber, como também e principalmente o uso inteligente e imaginativo dos terminais que conduzem o consulente ao estoque. Ensina-se, observa Lyotard, um manejo mais refinado desse jogo de linguagem a que se chama de pergunta: onde endereçar a pergunta? Ou seja: em que terminal da memória estocada professor e aluno podem encontrar a resposta pertinente e instigante para o que querem saber.

Chego à complementaridade do professor e aluno na pesquisa coletiva porque piso relativamente cedo a França (1961) e os Estados Unidos (1962). No primeiro caso, graças à bolsa de estudos para o doutorado em Literatura francesa, oferecida por aquele governo. No segundo, por contrato de trabalho para o ensino da Literatura Brasileira e da Portuguesa na universidade. ${ }^{12}$ De repente, aquilo que literalmente desconhecia, o Brasil-colônia e o período colonial da literatura brasileira (formado que fui, repito, pela Formação da literatura brasileira, que se inicia com os poemas do inconfidente Cláudio Manoel da Costa), se estatelava diante dos meus olhos juvenis em Paris. Vivi vicariamente a guerra da independência da Argélia. Estatelava-se, ainda, diante dos meus olhos de jovem profissional no contato que pude manter com os estudantes e familiares de origem indígena na cidade de Albuquerque. ${ }^{13}$ Daí parte do meu interesse posterior

11 A edição brasileira contou com prefácio escrito pelo entrevistado.

12 Sentia-me relativamente à vontade em Portuguesa. Lembro que um dos grandes mestres que tive na graduação foi Manuel Rodrigues Lapa. Ele preparava então a edição das Cartas chilenas e organizava sua notável antologia das Cantigas d'escarnho e de mal dizer dos cancioneiros medievais galego-portugueses.

13 Para evitar mal-entendido, não me refiro neste momento aos mexicanos imigrantes (chamados chicanos), mas a famílias ainda moradoras em pueblos, como os próximos a Santa Fé ou Taos. Nunca poderei esquecer o dia em que fui convidado por aluno a jantar com os pais. Entrei na casa de aparência externa pequeno-burguesa, mas todo o chão do interior da residência era de terra batida. 
por Derrida (pois é dele que estamos sempre falando). Judeu argelino, por um lado. Leia-se L'autre cap. Notável leitor de Lévi-Strauss, por outro lado. Leiam-se os belos ensaios dele sobre Tristes tropiques em L'écriture et la différence e De la grammatologie. ${ }^{14}$ Da minha parte, escrevi longo ensaio, "A viagem de Lévi-Strauss aos trópicos" (O cosmopolitismo do pobre).

A essa experiência de vida dei o nome de descarrilamento. O vírus colonial lusitano passa a me afetar no cotidiano europeu tomado pelos plásticos explosivos (plastic) dos argelinos e resolvo tratá-lo com afeto (afinal o vírus é parte indireta da minha formação) e criticamente. Com o corpo tomado por virose pós-colonial, torno-me febril e deliro. Instruído pelos intelectuais e escritores africanos e pela França, apaixono-me pela poesia de Aimé Césaire. Leio as revistas Temps Modernes e Présence Africaine e, marinheiro de primeira viagem, eu me escandalizo com a tomada do Teatro Odéon por tropa da OAS (Organisation de l'Armée Secrète) que decreta, no dia da estreia da peça, a proibição de Les paravents, de Jean Genet. Entendo de censura avant la lettre. ${ }^{15}$

É evidente que, do ponto de vista estreito do jovem de 18 anos que tem acesso às nossas letras pelos dois notáveis volumes da Formação da Literatura Brasileira, posso afirmar - pela experiência de vida e de arte em Paris e pelo trabalho docente em Albuquerque - que sistema algum de pensamento está também isento de descarrilamento imprevisto no calendário e na agenda. Em outras palavras, sistemas influentes de pensamento não são autoimunes, embora este ou aquele paradigma, este ou aquele sistema tenha sido apetrechado em favor da própria imunidade e contra todo e qualquer vírus. É o caso do sistema literário proposto por Candido, centrado no conceito de formação. O conceito não visa a, embora acabe por, imunizar o estudante contra o vírus colonial.

Reajo à imunização (e ao conceito de formação) nos cursos que ministro - a partir de setembro de 1962 - na Universidade do Novo México

\footnotetext{
14 Aliás, foi esse o primeiro tópico da primeira conversa que mantive com Derrida, na Johns Hopkins University. O encontro está descrito em trabalho que escrevi e li no simpósio organizado na Argélia em torno de admiradores do filósofo. Cf. "La troisième rive proposée par les écrits de Jacques Derrida”. A palestra já foi publicada na França. Infelizmente, não tenho os dados bibliográficos.

${ }_{15}$ Cf. "Repressão e censura no campo das artes na década de 70" (Vale quanto pesa).
} 
sobre literatura brasileira e, desde então, onde sou contratado como professor ou palestrante. ${ }^{16}$

4. Ainda nesse prisma, gostaria de compartilhar com o senhor uma afirmação de Idelber Avelar (hoje professor de Teoria Literária na Universidade de Tulane, nos EUA), em uma entrevista que ele me concedeu. Bem, assim ele disse, quando eu lhe perguntei sobre os "ensaios de identidade nacional" e a obra de Candido: "O peso da tradição do ensaísmo de identidade nacional é muito grande; é uma tradição que conseguiu elaborar uma língua muito abarcadora; ela é uma língua sem um exterior. Uma espécie de um hegelianismo dos trópicos”. Nesse sentido, a questão que coloco é pautada sobre esta formulação de um "hegelianismo dos trópicos" (que me parece justa em sua redução); isto é, como o senhor situaria a "desconstrução" em relação a uma "crítica da realidade brasileira" identificada por Idelber Avelar como um "hegelianismo dos trópicos"? Quer dizer, o que o senhor destacaria, do ponto de vista dessa formulação, se ela lhe parecer aceitável?

A resposta não é simples, e é por isso que nunca é recomendável respondê-la pelos pontos mais salientes. A razão é simples. A saliência sempre deixa em aberto a brecha. E espertos sempre aproveitam da brecha (evidente) para exercerem a crítica destruidora. Mas o exercício da honestidade intelectual me obriga a subscrever o contrato que existe subjacente à concessão de entrevista. Só vale pular o que é julgado impertinente. A pergunta não o é. Faz sentido. E na falta da possível elaboração mais complexa, tomo um atalho. Tomo, como exemplo, os colegas de cultural studies que estudam a questão da identidade em situação diaspórica. Elejo Stuart Hall.

Poderia ter elegido um exemplo bem anterior a Hall, Roger Bastide, notável pilar da Universidade de São Paulo. Por que não falar dele antes de Stuart Hall? Já Roger Bastide ao tentar configurar a identidade do africano no Brasil recorria à metáfora da viagem. Refiro-me ao célebre conceito

16 O que chamo de virose colonial pouco ou nada tem a ver com a crítica a Candido por Haroldo de Campos. O poeta concreto permanece no campo das belles lettres e apenas assinala o sequestro na Formação da literatura brasileira de um estilo-de-época, o Barroco. Faço o esclarecimento para que se sintonize a que episteme da história literária ele pertence. À velha estilística, evidentemente. 
que desenvolve em 1954, ao publicar o ensaio "Le principe de coupure et le comportement afro-brésilien” (1954), onde discute o até então tema tabu sobre a "identidade" dos africanos no Brasil.

O "princípio do corte" instituía a viagem entre dois mundos sociais e culturais como índice da não-marginalidade, na nossa nação, do grupo étnico diaspórico (se se pode usar palavra tão elegante para o que foi simplesmente a escravidão negra no Brasil). Ao mesmo tempo e serenamente - defendia Bastide -, o afro-brasileiro podia ser adepto fervoroso do candomblé (em país onde o praticante era perseguido pela polícia da elite dominante, naturalmente europeia) e agente econômico perfeitamente adaptado à racionalidade moderna. Compete ao leitor desta entrevista, traçar a que outros caminhos teóricos o princípio enunciado por Bastide pode conduzir.

Da minha parte, retomo-o em Stuart Hall ${ }^{17}$ Ao contrário do francês Roger Bastide, que centrava na questão religiosa o interesse de sua pesquisa sobre os afro-brasileiros, Hall se deixou motivar por uma vertente cultural ampla e pós-moderna, abrindo a porta de entrada da universidade britânica para o que será mais tarde denominado "Cultural Studies". Na diáspora afro-caribenha, Hall salienta uma "rede e um local de memória”, que são definidos pela "família ampliada", pela família aquém e além-mar. O principal interesse do jamaicano é o de desmistificar o processo único de assimilação identitária, que, a partir de meados do século 19, circunscreveu a um exclusivo e soberano Estado-nação do Novo mundo a aculturação de todo e qualquer imigrante europeu e de todos os ex-escravos africanos.

Por esse processo de mão única, já em meados do século 20, a “terceira geração" de antigos escravos ou de imigrantes pouco ou nada guardava das origens, como se lê na bibliografia canônica sobre os processos de americanização, de mexicanização ou de abrasileiramento. Ou, como está na célebre frase de Margaret Mead, escrita durante a Segunda Grande Guerra, "Somos todos terceira geração”. Ao fazer a afirmação, a antropóloga apresentava sem diferença tanto os preconceitos e as discriminações quanto os amálgamas econômicos e raciais, encontrados no tecido social ianque. Ninguém (?) era mais "second class citizen", embora houvesse os que fossem e formavam multidão. Indiscriminadamente, os pracinhas

17 Desenvolverei o raciocínio a partir do ensaio "Pensando a diáspora - reflexões sobre a terra no exterior", parte da antologia de Stuart Hall publicada sob o título de Da diáspora pela Editora da Universidade Federal de Minas Gerais, em convênio com a Unesco. 
“norte-americanos" iriam combater juntos e unidos e no estrangeiro as forças malignas do Eixo. De volta à casa, esse era outro problema, não previsto na tese da terceira geração.

Ao desmistificar o processo oitocentista de assimilação do imigrante pela nação de destino, processo de aculturação sempre verossímil se a migração for ocidental e branca, Hall lança as bases para teorizações que instituem uma configuração identitária plurívoca para os afrodescendentes caribenhos que optaram pelo exílio e o trabalho em terras britânicas. Eles ainda mantêm contato estreito com as ilhas de origem. O canal crucial e permanente é a "família ampliada", em situação semelhante à das levas de wet-backs mexicanos e dos trabalhadores manuais porto-riquenhos que, no século passado, fixaram residência na Califórnia e na região de Nova Iorque..$^{18}$ No entanto, segundo Hall, a questão identitária do afrodescendente no Reino Unido não pode reduzir-se a essa viagem de mão dupla. A questão da identidade, se compreendida apenas como tal, serve de campo para o exercício mais eficaz da discriminação e do preconceito pelos poderosos locais. Daí a complexidade polêmica da sua análise.

Ao elo de pertencimento tanto ao solo britânico quanto a essa ou aquela ilha de origem, Hall acrescenta novo dado: a condição de "ser caribenho" em solo europeu. A desconstrução da diáspora pela identidade múltipla é lançada ao etnocentrismo (ao "hegelianismo dos trópicos", se quiser) sob a forma de paradoxo.

À maneira de um cosmopolita aristocrático brasileiro (por exemplo, Paulo Prado no prefácio a Poesia Pau-Brasil, que descobre ser brasileiro em plena Place Clichy), Hall afirma com dose de autoironia que a sua condição de jamaicano “tornou-se 'caribenha', não no Caribe, mas em Londres". Ao terceiro elo identitário, legitimamente londrino, somam-se (1) o pertencimento dos "caribenhos" a outras e emergentes identidades "britânicas negras", (2) as (re)identificações simbólicas com as culturas propriamente africanas e, mais recentemente, (3) com as culturas afro-americanas que se expressam pela vertente popular ou pop. Refiro-me ao jazz, ao rock\&roll e à MPB - todos equidistantes do reggae jamaicano e semelhantes. Refiro-me, ainda, à luta de boxe, ao beisebol e ao futebol.

18 Nesse caso específico, ouso recomendar ensaio meu intitulado As raízes e o labirinto da América Latina (Rocco), em que faço a leitura de Octavio Paz e da figura conhecida como el pachuco. 
Neste ano, o problema do afro-europeu nos esportes ganhou destaque na imprensa internacional.

É dessecaldo cultural complexo que surgea polimorfa "jamaicanidade" para Stuart Hall, principal motivação política e pessoal para o desentendimento que teve com os colegas marxistas da New Left Review, a que pertencia por ser um dos fundadores; motivação agora institucional para a sua transferência para o Chelsea College, da Universidade de Londres, onde ganhou a cena urbana contemporânea como professor. Passa a ensinar mídia, cinema e cultura popular. De Londres é que dará o salto definitivo para a Universidade de Birmingham, onde se transformará em fundador e diretor do Centre for Contemporary Cultural Studies.

Ao paradoxo da identidade diaspórica se soma, em Hall, o resgate da subjetividade pós-colonial, que ele quer incorporar à tradição marxista britânica. Repito-me: esse resgate não está isento de vínculos com as teorias sobre a pós-modernidade, com a desconstrução derridiana e com os estudos de gênero (gender studies). Por outro viés, o resgate da subjetividade pós-colonial aproxima o jamaicano de outro grupo étnico nitidamente pós-colonial, que é o dos indianos no mundo anglo-saxão, de que é melhor exemplo a professora Gayatri Spivak (cf. The post-colonial critic, publicado pela Routledge), da Columbia University nos Estados Unidos da América.

Já está claro que a leitura dos clássicos do marxismo interessa mais a Hall no contexto do colonialismo europeu e menos no contexto do capitalismo ocidental. O "ser privado" se intromete nos seus escritos teóricos com a elegância e o despudor da escrita memorialista ou autobiográfica. Ao transformar as amarras com o estritamente pessoal em programa político da diáspora pós-colonial, a escrita teórica subjetiva carrega de tonalidades dramáticas o que apenas teria sido mais uma página de pensador europeu (leia-se: de jamaicano europeizado), ou mais um lamento de deserdado.

O discurso crítico de Stuart Hall tem estatuto, pois se situa dentro e fora do teórico, dentro e fora do autobiográfico. Esseéo modo como concilia a constatação de ter sido preparado a ser inglês pela formação colonial com o fato de que, em tempos pós-coloniais, nunca será legitimamente inglês; e é também o modo como se dá conta de que, pela diáspora afro-caribenha, tinha se distanciado da condição original jamaicana para estar sempre "chegando" (o verbo é evidentemente dele) à Europa. 
Como nos escritos de Roger Bastide, a "viagem" do afro-caribenho entre dois continentes, entre dois mundos sociais e culturais, é real e é simbólica. Ele só pode se integrar (se se pode dizer que está se integrando) ao mundo anglo-saxão se operar cortes e recortes identitários. Continua Hall, agora comentando a clivagem de que é feita a identidade jamaicana na Europa: "Conheço intimamente os dois lugares, mas não pertenço completamente a nenhum deles. E essa é exatamente a experiência diaspórica, longe o suficiente para experimentar o sentimento de exílio e perda, perto o suficiente para entender o enigma de uma 'chegada' sempre adiada”.

A condição existencial é que o leva a não acatar a distinção entre o ser público e o ser privado. Explica-se: "Aprendi [...] que a cultura era algo profundamente subjetivo e pessoal e, ao mesmo tempo, uma estrutura em que a gente vive".

\title{
SILVIANO SANTIAGO AND THE DECONSTRUCTION:
}

\begin{abstract}
This is an interview granted by Silviano Santiago on August 14, 2016. He was born in Formiga, Minas Gerais. He is now 80 years old and is the author of a vast intellectual and artistic work, having started his education in Literature in Brazil and completing it in France with a PhD defense at the Sorbonne in 1968. Silviano was also a professor in Brazil (PUC-Rio) and abroad, Canada and the United States, passing through the universities of Rutgers, Toronto, New York, Buffalo, Indiana and New Mexico. I emphasize that the interview that follows below does not have a biographical character, turning therefore to the activity of Silviano Santigo in the Brazilian intellectual debate with respect to the literary critic. In this sense, I ask Silviano Santiago about his reading of Derrida's work, his role in the dissemination of this author's thinking in Brazil since 1976, and the effects of the Derridean concept of deconstruction on the renewal promoted by Silviano of the interpretations of history of Brazilian literature, with deconstruction being one of the main theoretical bases of what has come to be called a postcolonial perspective within cultural studies in the human sciences.
\end{abstract}

Keywords: Silviano Santiago; deconstruction; postcolonialism. 